\title{
PROGRESS WITH THE SYNCHROTRON LIGHT SOURCE ALBA
}

\author{
D.Einfeld, E. Al-Dmour, J.Campmany, M.Muñoz, F.Pérez, and M.Pont
}

\author{
CELLS, P.O. Box 68, 08193 Bellaterra, Spain
}

\begin{abstract}
ALBA will be a third generation synchrotron light facility to be built in Cerdanyola near Barcelona (Spain). Commissioning of the storage ring is foreseen to start at the end of 2008. The design phase of ALBA is almost completed and the first components are ready to be ordered. A $100 \mathrm{MeV}$ LINAC will inject electrons into a nominal energy booster synchrotron of similar circumference as the storage ring, so that both accelerators will share the same tunnel. The storage ring, working at $3 \mathrm{GeV}$ with a circumference of $268.8 \mathrm{~m}$, has been designed for a maximum current of $400 \mathrm{~mA}$. The lattice is based on an extended DBA structure and has a nominal emittance of $4 \mathrm{~nm}$.rad. The machine has a four fold symmetry with 4 long straight sections $(8 \mathrm{~m}), 12$ medium $(4.2 \mathrm{~m})$ and 8 short $(2.6 \mathrm{~m})$. This report concentrates on recent design developments, component choices and current status. Another paper at this conference deals with accelerator physics issues.
\end{abstract}

\section{INTRODUCTION}

The responsibility for the construction (and future operation) of the ALBA facility belongs to the Consortium for the Construction, Equipping and Exploitation of the Synchrotron Light source (CELLS). CELLS is funded on the basis of an equal share between the MEC (Ministerio de Educación y Ciencia) of the Spanish Government and the DURSI (Departament d'Universitats, Recerca i Societat de la informació) of the Generalitat de Catalunya.

Since beginning of 2004 the team for CELLS is being constituted and the detailed design of the $3 \mathrm{GeV}$ Synchrotron Light Source is almost finished. Several Call for Tenders have been launched and we expect that by the end of 2005 the main components of the accelerator complex will have been ordered.

\section{STORAGE RING}

\section{Lattice}

The objectives of the lattice design were the following:

- Horizontal cross section below $150 \mu \mathrm{m}$

- Vertical cross section around $7 \mu \mathrm{m}$

- Lifetime longer than $10 \mathrm{~h}$

- Lattice energy acceptance larger than $3 \%$

- As many straight sections as possible

- Circumference smaller than $270 \mathrm{~m}$

A lattice which fulfils the above requirements has been designed and it has an extended DBA structure.
Around $38 \%$ of the circumference is devoted to straight sections. A detailed description of the lattice can be found in [1]. Figure 1 shows the lattice functions in one quarter of the storage ring.

Table 1: Main parameters of the storage ring

\begin{tabular}{|l|c|}
\hline Energy & $3 \mathrm{GeV}$ \\
\hline Circumference & $268.8 \mathrm{~m}$ \\
\hline Current & $400 \mathrm{~mA}$ \\
\hline Tunes & $18.178 / 8.37$ \\
\hline Chromaticity & $-39 /-27$ \\
\hline Emittance & $4.3 \mathrm{~nm} . \mathrm{rad}$ \\
\hline Beam size $\sigma_{\mathrm{x}} / \sigma_{\mathrm{y}}$ & \\
Mid $4 \mathrm{~m}$ straight & $132 / 7.4$ \\
Mid bending & $49 / 32$ \\
\hline \# straight sect. & 24 \\
\hline \# possible id's & 17 \\
\hline
\end{tabular}

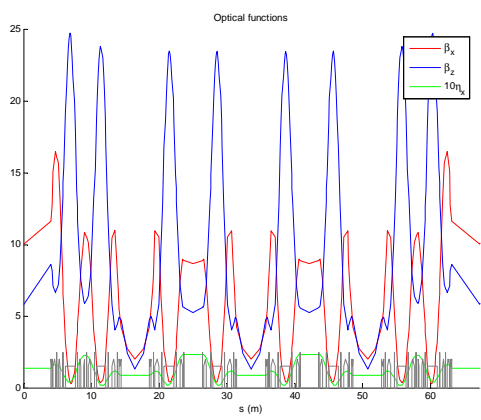

Figure 1: Machine functions along $1 / 4$ of the ring.

\section{Magnets System}

All magnets have been designed in $3 \mathrm{~d}$ using the TOSCA code. The combined magnet will be C-shaped, curved with parallel ends. The central field is $1.42 \mathrm{~T}$ and the gradient is $5.65 \mathrm{~T} / \mathrm{m}$. The main parameters of the quadrupoles and sextupoles can be found in table II.

Table 2: Main parameters for quads and sextupoles

\begin{tabular}{|l|c|c|}
\hline & Quadrupoles & Sextupoles \\
\hline Number & $24 / 24 / 48 / 16$ & $56 / 64$ \\
\hline Length, $\mathrm{mm}$ & $530 / 310 / 260 / 200$ & $220 / 150$ \\
\hline Bore, $\mathrm{mm}$ & $61 \mathrm{~mm}$ & $76 \mathrm{~mm}$ \\
\hline Force, $\mathrm{T} / \mathrm{m}, \mathrm{T} / \mathrm{m}^{2}$ & 23.4 & 700 \\
\hline Useful area & $\mathrm{x} \leq 20 \mathrm{~mm}$ & $\mathrm{x} \leq 20 \mathrm{~mm}$ \\
\hline
\end{tabular}

Only 10 quadrupoles will need to be of figure of 8 structure. The rest will be magnetically closed. The sextupoles can all have the same section. This has been 
achieved by placing the bending magnet radiation port not exactly in the middle but by changing it $\pm 1.5^{\circ}$ depending on the location. The sextupoles include horizontal and vertical steering coils (0.8 mrad both) as well as skew quadrupole.Each one of the quadrupoles will have its own power supply. The sextupoles will be powered per families and the combined magnets will all be in series.

\section{RF system}

The RF system should:

- Restore the energy loss by synchrotron radiation

- Provide a 3\% RF energy acceptance

- Do not induce couple bunch instabilities:

Longitudinal HOM impedance < $5 \mathrm{MOhm} . \mathrm{MHz}$

Transverse HOM impedance $<50 \mathrm{kOhm} / \mathrm{m}$

- Fit in the short straight section of the lattice

- Use "off the shelf" transmitters

The decision has been to use the normal conducting HOM damped cavity following the BESSY design [2], Figure 2, with a combination of $80 \mathrm{~kW} \mathrm{cw}$ IOT to produce the total power required. The power combination will be realised with a Cavity Combiner [3] (CaCo). Table III presents the main parameters of the RF system.

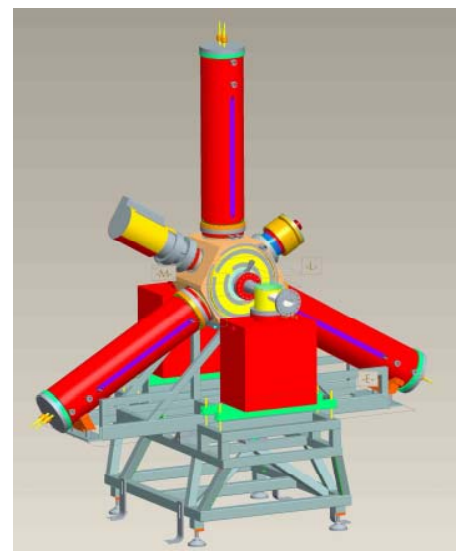

Figure 2: Sketch of the HOM damped cavity.

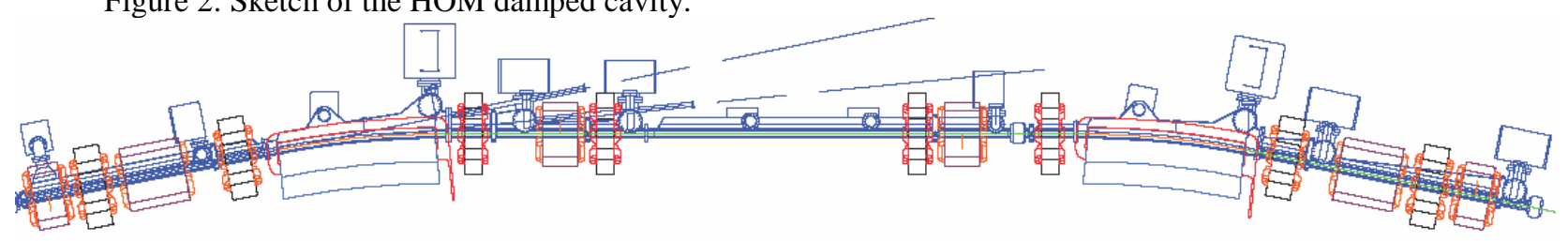

The unit cell

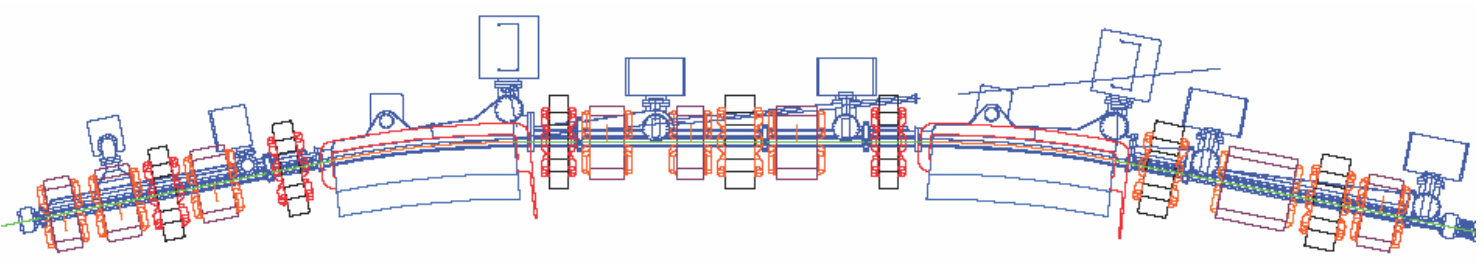

The matching cell

Figure 3: The vacuum chamber design for the unit and the matching cell.
Table 3: Main parameters of the RF system

\begin{tabular}{|l|c|}
\hline RF Voltage & $3600 \mathrm{kV}$ \\
\hline Beam current & $400 \mathrm{~mA}$ \\
\hline Losses (incl. ID's) & $1300 \mathrm{keV} /$ turn \\
\hline Beam power & $520 \mathrm{~kW}$ \\
\hline CAVITY & \\
\hline Insertion length & $\sim 500 \mathrm{~mm}$ \\
\hline Number & 6 \\
\hline Frequency & $500 \mathrm{MHz}$ \\
\hline Shunt Impedance & $>3.1 \mathrm{Mohm}$ \\
\hline Voltage/cavity & $600 \mathrm{kV}$ \\
\hline Input power coupler & $160 \mathrm{~kW}$ \\
\hline Cooling capacity & $>80 \mathrm{~kW}$ \\
\hline TRANSMITTER & \\
\hline Tube type & $\mathrm{IOT}$ \\
\hline Number & $2 \mathrm{x} 6$ \\
\hline Total power & $960 \mathrm{~kW}$ \\
\hline \multicolumn{2}{|}{} \\
\hline
\end{tabular}

The storage ring will be divided into 16 vacuum sections of two types: the unit cell and the matching cell. The sections will be separated by sector gate valves; see Figure 3. The vacuum chamber will be made of stainless steel with an electron beam vertical aperture of $28 \mathrm{~mm}$ and horizontal aperture of $72 \mathrm{~mm}$ with a slot $10 \mathrm{~mm}$ high and $20 \mathrm{~mm}$ wide to connect the vacuum chamber to the antechamber where crotch absorbers distributed all along the circumference will absorb the unwanted radiation. The maximum power density (with normal incidence) is $250 \mathrm{~W} / \mathrm{mm}^{2}$. The pumping will be by lumped ion pumps with addition of titanium sublimation pumps close to the main absorbers.

\section{Vacuum System}


The overall pumping speed is around $60000 \mathrm{1} / \mathrm{s}$; this will maintain an average dynamic pressure of $1.10^{-9} \mathrm{mbar}$ to achieve a beam lifetime of 10 hours at the designed current after the commissioning of the machine. No insitu bake out is foreseen for the vacuum vessels

\section{INJECTOR}

The injector will consist of a $100 \mathrm{MeV}$ linac, a $3 \mathrm{GeV}$ Booster synchrotron and the two transfer lines.

Table 4: Main parameters of the linac

\begin{tabular}{|l|c|}
\hline Energy & $100 \mathrm{MeV}$ \\
\hline Multibunch charge & $\geq 3 \mathrm{nC}$ \\
\hline Multibunch length & $300 \mathrm{~ns}-1000 \mathrm{~ns}$ \\
\hline Single bunch charge & $\geq 1.5 \mathrm{nC}$ \\
\hline Emittance & $\leq 50 \mathrm{~mm} . \mathrm{mrad}$ \\
\hline Energy spread & $\leq 1.5 \%$ \\
\hline
\end{tabular}

The Linac will be a turn-key system. Single and multibunch operation modes will be possible also under top-up operation with charges as low as $50 \mathrm{pC}$ and with flexible pulse length formats.

The Booster of ALBA will have a large circumference, $249.6 \mathrm{~m}$ and will share the same tunnel as the storage ring. The lattice has a 4-fold symmetry. The main parameters of the Booster are presented in table $\mathrm{V}$.

Table 5: Main parameters of the Booster

\begin{tabular}{|l|c|}
\hline Peak energy & $3 \mathrm{GeV}$ \\
\hline Circumference & $249.6 \mathrm{~m}$ \\
\hline Current & $2 \mathrm{~mA}$ \\
\hline Tunes & $12.396 / 7.447$ \\
\hline Chromaticity & $-16.77 /-10.68$ \\
\hline Emittance at $3 \mathrm{GeV}$ & $9 \mathrm{~nm} . \mathrm{rad}$ \\
\hline Number of Bending & 40 \\
\hline Force, $\mathrm{T}, \mathrm{T} / \mathrm{m}$ & $0.87 / 2.3$ \\
\hline Number of quadrupoles & 44 \\
\hline Force, $\mathrm{T} / \mathrm{m}$ & 16 \\
\hline
\end{tabular}

Chromaticity will be corrected to +1 by appropriately shaping the poles of the combined magnets and of the quadrupoles. The addition of two families of sextupoles will guarantee flexibility.

\section{INSERTION DEVICES}

Five beam lines are funded to be built together with the storage ring in the first phase. The final selection of which beams lines to build is currently under discussion, after the decision of the Scientific Advisory Committee (SAC) to recommend the building of seven beam lines [4].

However, some generic IDs have been considered in order to discuss the performance of the lattice. These IDs have to be regarded as a first approach to what the users are demanding. The final decision about their periods and magnetic features will depend on the final decisions about the beam lines, so they are currently under discussion.

On this basis Figure 4 illustrates the spectral output from the present design using 3 generic IDs. A length of
$2 \mathrm{~m}$ has been considered for all insertion devices to make the comparison easier and a current of $250 \mathrm{~mA}$ has been taken for the determination of outputs. These three insertion devices have been considered to be:

- Conventional multipole wiggler (W60), maximum peak field $1.9 \mathrm{~T}$, period length $60 \mathrm{~mm}$

- In vacuum hybrid undulator (VU20), period of 20 $\mathrm{mm}$, minimum gap of $5.5 \mathrm{~mm}, \mathrm{~K} \max =1.8$

- $\quad$ APPLE-II type undulator (EU83), period of $83 \mathrm{~mm}$, minimum gap of $11 \mathrm{~mm}, \mathrm{~K}_{\mathrm{V}} \max =9.4$

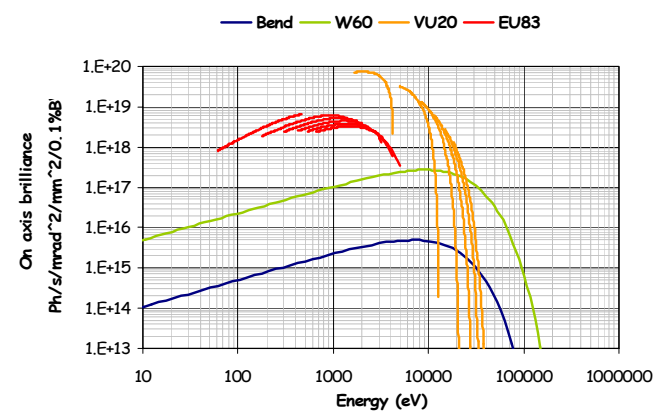

Figure 4: On axis brilliance for bending and 3 generic IDs.

\section{SITE AND BUILDING}

We have already awarded the contract to write the Executive Project for the building. Figure 5 shows a model of the building housing the Synchrotron facility. The vibrational studies have shown some problems which are at the moment being studied. On the other hand the geotechnical studies have not shown any significant movement of the site.

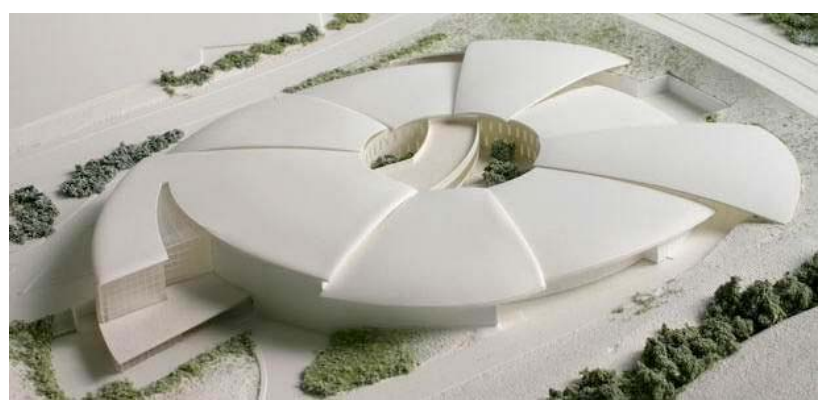

Figure 5: Model the ALBA building.

\section{REFERENCES}

[1] D.Einfeld, M.Muñoz, "Lattice for ALBA", These Proceedings

[2] F. Marhauser and E. Weihreter, "First Tests of a HOM-Damped High Power 500 MHz Cavity", EPAC 2004

[3] E. Wooldridge et al, "Combining Cavity for RF Power Sources: Computer Simulation and Low Power Model" EPAC 2004

[4] See http://www.cells.es/NewsAndEvents/News 